\title{
Neural Network Control for PPDCV Clinker Cooler System
}

\author{
Majid Ahmed Oleiwi, Ph.D \\ Associate Prof. \\ University of Technology \\ Control \& Systems Engineering
}

\author{
Zaid Abed aljasem \\ Engineer \\ University of Technology \\ Control \& Systems Engineering
}

\begin{abstract}
Pilot Proportional Directional Control Valve (PPDCV) is used to control the clinker cooler actuator position for Cement Industries. PID controllers are satisfying control for the actuator position control with transient response and reduce steady state error. Uncertainty parameter cause unsmooth response small oscillation in actuator position. This work explains a neural network control for (PPDCV) system with uncertainty parameter, reduces the disturbance, and removes the oscillation in the response. The paper is focused on the possibilities of applying trained artificial neural networks for creating the system inverse models that are used to design inverse control algorithm for non-linear dynamic system. The simulation experiment is performed using Matlab and Simulink to show the response of these controllers.
\end{abstract}

\section{Keywords}

Neural Network; PPDCV; Clinker Cooler Servo System; Simulation

\section{INTRODUCTION}

Pilot Proportional Directional Control Valve (PPDCV) has been used in modern industrial applications. It gives ability to apply high forces for industrial applications. The dynamic behavior of (PPDCV) is highly nonlinear due to the phenomenon such as pressure-flow characteristics.

PID controller or any it's component with fixed parameters $K_{p}$, $\mathrm{K}_{\mathrm{i}}$ and $\mathrm{K}_{\mathrm{d}}$ is the most popular controller used for industry applications, because it can improve transient and steady states error. PID cannot satisfy the performance requirement under nonlinear complex system, uncertainty parameters, and unavailable accurate system model.

To reduce all these problems, artificial neural network $(\mathrm{NN})$ is used for nonlinear systems. The purpose of neural network control is to create an inverse model, when the model of the plant is not well known and available input - output data. The advantage of used the inverse control by $\mathrm{NN}$ is to cancel the nonlinearities in the process and therefore it must be very accurate $[1,2]$.

Neural network is a good tool for control the systems that are difficult to model. It can cover a wider range of operating condition and can operate with noise and disturbance with different nature in the complex ill-defined process.

There are many researchers used the neural network control for hydraulic systems. O. A. Dahunsi et al. used a PID controller in a feedback loop and a neural network feed forward controller for the suspension travel to improve the vehicle ride comfort and handling quality. A SISO neural network (NN) model was developed using the input-output data set obtained from the mathematical model simulation [3]. A. A. Mozafari and M. Lahroodi used an Artificial Neural Network (ANN) based on modeling technique for prediction the outlet temperature, pressure and mass flow rate of gas turbine combustor in order to ensure the safe and automatic operation of the engine [4].Ammar A. Aldair and Weiji J. Wang used artificial intelligence neural control technique for full vehicle nonlinear active suspension systems. Neural controller is devised to adjust the hydraulic actuators forces to minimize the vertical displacement at each suspension point [5].A. Khajekaramodin et al. used an inverse neural network model to replicate the inverse dynamics of the magneto rheological (MR) damper. They also designed linear quadratic Gaussian (LQG) controller to produce the optimal control force. These two controllers are link to control the structure [6]. Wenjun Meng et al. explained two control strategies, Neural Network Controller (NNC) and Passivity Based Controller (PBC), to control the speed of Aero Hydraulic Pump (AHP) for measuring its properties. These control strategies were used because test system for Aero Hydraulic Pump (AHP) has many nonlinear characteristics [7].Zhen-Yuan Jia et al. used a prediction method (G-ANFIS for short) based on grey correlation and adaptive neuron-fuzzy system (ANFIS) to forecast synthesis characteristics of hydraulic valve in the industrial production [8]. Jyh-Chyang Renn and Tsung-Han used two controllers, which are conventional PID controller and neural network controller, for control a new quarter servo-hydraulic vehicle active suspension system [9]. Neural network are able to generate input and output mapping and approximate the plant dynamics as a black box model.

From the literature review above, the is no one used neural network to control PPDCV system in cement industry. In this paper Neural Network is used as the inverse control for controlling PPDCV without any oscillated response

\section{SYSTEM BACKGROUND}

\subsection{Proportional Valve}

The Proportional valve is the function that provides pressure or force via electrical signal or via remote. To move the spool, force of the solenoid must be greater than or equal the spring force. Electronic card in the proportional solenoid is used in this valve. An electrical voltage in the range $\left[\begin{array}{ll}-10 & +10] \mathrm{V}\end{array}\right.$ acting upon an electrical amplifier. Fig.1 illustrates the proportional control valve with electronic card [10]. 


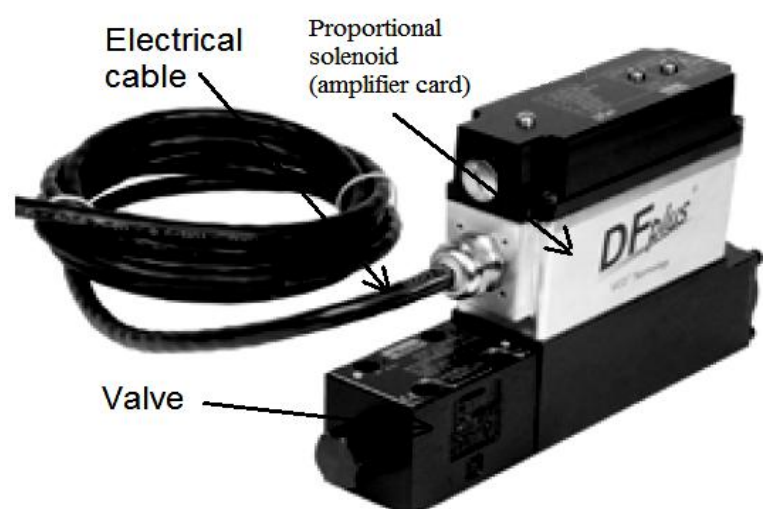

Fig.1: Proportional control valve [10]

\subsection{Pilot Proportional Directional Control Valve (PPDCV)}

In the modern since 2011, the clinker cooler of the cement industries used PPDCV but with new size that is the size of the pilot proportional valve is (10 NG) and size of the main valve is (25 NG). This system is used in Mass Cement Factory - Bazyan in Sulaimaniya-Iraq as shown below Fig.2.

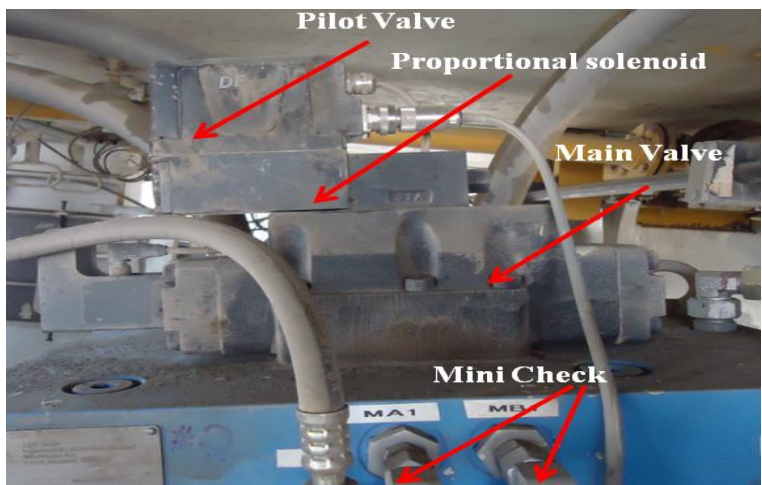

Fig.2 PPDCV size (25 NG) in Mass Cement Factory in Sulaimaniya-Iraq

A schematic diagram of PPDCV in the clinker cooler is the subject to the consideration in this work as shown in below Fig.3.

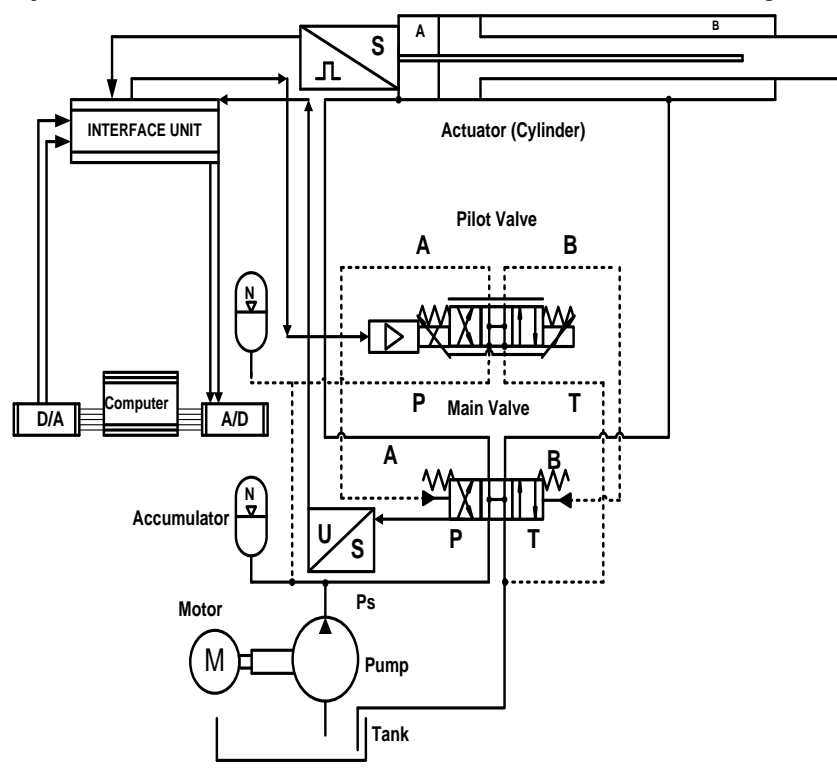

Fig.3 Schematic diagram for size (25 NG) PPDCV

The position of the actuator cylinder is measured with a displacement transducer built into the cylinder. The measured signal is used to compare with desired input for the realization of the controller algorithm. The pilot valve is four way 3- position proportional directional control valve. The main valve is also four way 3- position proportional directional control valve [11]. The position of the actuator is compared with the desired input given by the user. If these values differ, the solenoids of the pilot valve $\left(\mathrm{x}_{\mathrm{pil}}\right)$ are driven by the controller to change pilot flow of the hydraulic fluid that reaches to the main valve. This flow in turn causes a pressure differential $\left(\mathrm{p}_{1} \& \mathrm{p}_{2}\right)$ on the front surfaces of the control spool of the main stage so that the position of the main valve $\left(\mathrm{x}_{\text {main }}\right)$ is deflected and will change. The position of the main valve changes delivering or letting off pressure oil $\left(\mathrm{p}_{3} \& \mathrm{p}_{4}\right)$ of the actuator piston side $(\mathrm{A})$ and the actuator rod side (B) of the cylinder, respectively, and it causes the actuator position $\left(\mathrm{x}_{\mathrm{act}}\right)$ change [15]. This diagram of the system is illustrated in Fig.4.

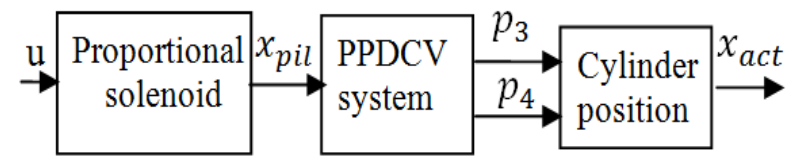

Fig.4 Block diagram of PPDCV

\section{MATHEMATICAL MODEL}

The nonlinear dynamic model of PPDCV system is shown in Fig.4. It consists of pilot valve that control the main valve, while the main valve is used to control the actuator. Physical law is needed to build the dynamic model of this system. The dynamic model of Pilot proportional valve can be described by the second order differential equation.

$$
\ddot{x}_{\text {pil }}+2 \xi w_{n} \dot{x}_{\text {pil }}+x_{\text {pil }} w_{n}^{2}=\mathrm{kw}_{\mathrm{n}}^{2} \mathrm{u}
$$

Where $\left(\mathrm{x}_{\mathrm{pil}}\right)$ is the position of the pilot valve, $(\mathrm{u})$ is the input voltage, $\left(w_{n}\right)$ is the natural frequency, $(k)$ is the pilot proportional valve gain, and $(\xi)$ is damping ration of the pilot proportional valve.

The dynamics of almost all practical hydraulic components of the PPDCV can be appropriately described by the following equations $[11,12]$.

The flow equations of the pilot valve can be represented by the following term:

For extension

$$
\begin{aligned}
& \mathrm{q}_{1}=\mathrm{c}_{\mathrm{dpil}} \mathrm{w}_{\text {pil }} \mathrm{x}_{\text {pil }} \sqrt{\frac{2}{\rho}\left(\mathrm{p}_{\mathrm{s}}-\mathrm{p}_{1}\right)} \\
& \mathrm{q}_{2}=\mathrm{c}_{\mathrm{dpil}} \mathrm{w}_{\text {pil }} \mathrm{x}_{\text {pil }} \sqrt{\frac{2}{\rho}\left(\mathrm{p}_{2}-\mathrm{p}_{\mathrm{t}}\right)}=
\end{aligned}
$$

For retraction

$$
\begin{aligned}
\mathrm{q}_{1} & =\mathrm{c}_{\mathrm{dpil}} \mathrm{w}_{\text {pil }} \mathrm{x}_{\mathrm{pil}} \sqrt{\frac{2}{\rho}\left(\mathrm{p}_{1}-\mathrm{p}_{\mathrm{t}}\right)} \\
\mathrm{q}_{2} & =\mathrm{c}_{\text {dpil }} \mathrm{w}_{\text {pil }} \mathrm{x}_{\text {pil }} \sqrt{\frac{2}{\rho}\left(\mathrm{p}_{\mathrm{s}}-\mathrm{p}_{2}\right)}
\end{aligned}
$$

The flow equations of the main valve can be represented by the following term:

For extension

$$
\mathrm{q}_{3}=\mathrm{c}_{\mathrm{dmain}} \mathrm{w}_{\text {main }} \mathrm{x}_{\text {main }} \sqrt{\frac{2}{\rho}\left(\mathrm{p}_{\mathrm{s}}-\mathrm{p}_{3}\right)}
$$


$\mathrm{q}_{4}=\mathrm{c}_{\mathrm{dmain}} \mathrm{w}_{\text {main }} \mathrm{x}_{\text {main }} \sqrt{\frac{2}{\rho}\left(\mathrm{p}_{4}-\mathrm{p}_{\mathrm{t}}\right)}$

For retraction

$$
\begin{gathered}
\mathrm{q}_{3}=\mathrm{c}_{\text {dmain }} \mathrm{w}_{\text {main }} \mathrm{x}_{\text {main }} \sqrt{\frac{2}{\rho}\left(\mathrm{p}_{3}-\mathrm{p}_{\mathrm{t}}\right)} \\
\mathrm{q}_{4}=\mathrm{c}_{\text {dmain }} \mathrm{w}_{\text {main }} \mathrm{x}_{\text {main }} \sqrt{\frac{2}{\rho}\left(\mathrm{p}_{\mathrm{s}}-\mathrm{p}_{4}\right)}
\end{gathered}
$$

Where $q_{1}, q_{2}$ represent the fluid flows into and out of the pilot valve, respectively, $c_{\text {dpil }}$ is pilot valve coefficient of discharge, $\rho$ is the fluid density, $\mathrm{w}_{\mathrm{pil}}$ is width of the pilot valve port, $\mathrm{p}_{\mathrm{s}}$ is the pump pressure, $p_{1} \& p_{2}$ is the input and output pressure of the pilot valve respectively and $p_{t}$ is return pressure, $q_{3}, q_{4}$ represent the fluid flows into and out of the main valve, respectively, $\mathrm{c}_{\mathrm{dmain}}$ is main valve coefficient of discharge, $w_{\text {main }}$ is width of the main valve port, $p_{3}$ is the input pressure to actuator in the piston side, and $\mathrm{p}_{4}$ is the line pressure in rod side.

If internal and external leakage is neglected, hydraulic pressure behavior for compressible fluid volume is given by the following differential equation [11]

$$
\begin{aligned}
& \dot{\mathrm{p}}_{1}=\left(\frac{1}{\mathrm{C}_{\mathrm{f} 1}}\right)\left(\mathrm{q} 1-\mathrm{A}_{\text {main }} * \frac{\mathrm{dx}_{\text {main }}}{\mathrm{dt}}\right) \\
& \dot{\mathrm{p}}_{2}=\left(\frac{1}{\mathrm{C}_{\mathrm{f} 2}}\right)\left(\mathrm{A}_{\text {main }} * \frac{\mathrm{dx}_{\text {main }}}{\mathrm{dt}}-\mathrm{q} 2\right)
\end{aligned}
$$

Where $\left(\mathrm{C}_{\mathrm{f} 1} \& \mathrm{C}_{\mathrm{f} 2}\right)$ are the fluid capacitances, and $\mathrm{x}_{\text {main }}$ is the position of the main valve and $A_{\text {main }}$ is the effective Area of the main valve.

On the main side, the force developed by the main valve $\left(\mathrm{f}_{\text {main }}\right)$ is representing the pressure different between the spool of the main, which, in turn result from flow entering and leaving the main valve. This system can be described by the following equation:

$\mathrm{f}_{\text {main }}=\left(\mathrm{p}_{1}-\mathrm{p}_{2}\right) \mathrm{A}_{\text {main }}$

The mechanical part of the main valve can be described by the following dynamic equation:

$$
\mathrm{M}_{\text {main }} \ddot{\mathrm{x}}_{\text {main }}=\mathrm{A}_{\text {main }}\left(\mathrm{p}_{1}-\mathrm{p}_{2}\right)-\dot{\mathrm{x}}_{\text {main }} \mathrm{b}_{\text {main }}-\mathrm{x}_{\text {main }} \mathrm{k}_{\text {main }}
$$

Where

$\mathrm{M}_{\text {main }}$ is the mass of the main valve, and $\mathrm{k}_{\text {main }}$ b $\mathrm{b}_{\text {main }}$ are main valve stiffness and main valve viscous damping coefficient, respectively.

Hydraulic pressure behavior of the actuator for compressible fluid volume is given by the following differential equation [11]

$\dot{\mathrm{p}}_{3}=\left(\frac{1}{\mathrm{c}_{\mathrm{fA}}}\right)\left(\mathrm{q} 3-\mathrm{A}_{\mathrm{actA}} * \frac{\mathrm{dx}_{\mathrm{act}}}{\mathrm{dt}}\right)$

$\dot{\mathrm{p}}_{4}=\left(\frac{1}{\mathrm{C}_{\mathrm{fB}}}\right)\left(\mathrm{A}_{\mathrm{actB}} * \frac{\mathrm{dx}_{\mathrm{act}}}{\mathrm{dt}}-\mathrm{q} 4\right)$

On the hydraulic actuator, the actuator force $\left(\mathrm{f}_{\mathrm{act}}\right)$ is represent the pressure different between the actuator piston area $\left(\mathrm{A}_{\mathrm{act} A}\right)$ and actuator annulus area $\left(\mathrm{A}_{\mathrm{actB}}\right)$, which in turn result from flow entering and leaving the actuator

$\mathrm{f}_{\mathrm{act}}=\mathrm{p}_{3} \mathrm{~A}_{\mathrm{actA}}-\mathrm{p}_{4} \mathrm{~A}_{\mathrm{actB}}$

The mechanical part of the actuator can be described by the following differential equation

$$
\mathrm{M}_{\mathrm{act}} \ddot{\mathrm{x}}_{\mathrm{act}}=\left(\mathrm{p}_{3} \mathrm{~A}_{\mathrm{actA}}-\mathrm{p}_{4} \mathrm{~A}_{\mathrm{actB}}\right)-\dot{\mathrm{x}}_{\mathrm{act}} \mathrm{b}_{\mathrm{act}}-\mathrm{x}_{\mathrm{act}} \mathrm{k}_{\mathrm{act}}
$$

Where

$\mathrm{M}_{\mathrm{act}}$ is the actuator mass, $\mathrm{k}_{\mathrm{act}}$ is the actuator stiffness, and $\mathrm{b}_{\mathrm{act}}$ is the actuator viscous damping coefficient.

\section{CONTROLLER DESIGN}

This section illustrates the controller design for control the position of the actuator of (PPDCV) that depends on the differential equation of the plant model and the desired input.

\subsection{PID Controller}

This controller proportional-integral-derivative (PID) algorithm is used as the following equation:

$$
u(t)=K_{p} e(t)+K_{d} \frac{d}{d t} e(t)+K_{p} \int e(t) d t
$$

Where

$\mathrm{K}_{\mathrm{P}}, \mathrm{K}_{\mathrm{D}}$ and $\mathrm{K}_{\mathrm{I}}$ are the proportional, derivative, and integral gains for the controller, (e) is the error between the desire position of actuator with the actual position of the actuator.

\subsection{Neural Network Control}

Neural networks are a tool for control the nonlinear system. Neural network are too complex in relation to control the most nonlinear systems, so that the control strategy based on the neural network is too flexible [2].

The neural network control can be simple, and it has the ability to learn the nonlinear relations from a set input-output data. The inverse control is used to control the PPDCV system. The inverse control method can be used, if the inverse relationship between the input and output of a nonlinear system is found. We consider for example, the time-invariant nonlinear system given by the following equation for the output $(\mathrm{y})$ and the control action $(\mathrm{u})$ :

$$
\begin{gathered}
\mathrm{y}(\mathrm{k})=\mathrm{f}(\mathrm{y}(\mathrm{k}-1), \ldots \ldots, \mathrm{y}(\mathrm{k}-\mathrm{n}), \mathrm{u}(\mathrm{k}-1), \mathrm{u}(\mathrm{k}-2), \ldots \ldots, \mathrm{u}(\mathrm{k} \\
-\mathrm{m}))
\end{gathered}
$$

We can obtain (u) from the equation above by inverse this equation

$$
\begin{gathered}
\mathrm{u}(\mathrm{k})=\phi(\mathrm{y}(\mathrm{k}+1), \mathrm{y}(\mathrm{k}), \ldots \ldots, \mathrm{y}(\mathrm{k}-\mathrm{n}+1), \mathrm{u}(\mathrm{k}-1), \ldots, \mathrm{u}(\mathrm{k} \\
-\mathrm{m}+1))
\end{gathered}
$$

We replace y $(\mathrm{k}+1)$ by $\mathrm{r}(\mathrm{k}+1)$. The inverse controller is based on the inverse model such that the control system follows the command as shown in below Fig.5.

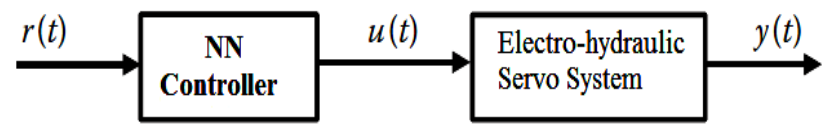

Fig.5 Inverse Neural Network controller

The training is carried out to minimize the error between the outputs of the actual control action(u) with output of the neural network $(\widehat{u})$. The schematic diagram for this training for the inverse control is shown in below Fig.6 [1]

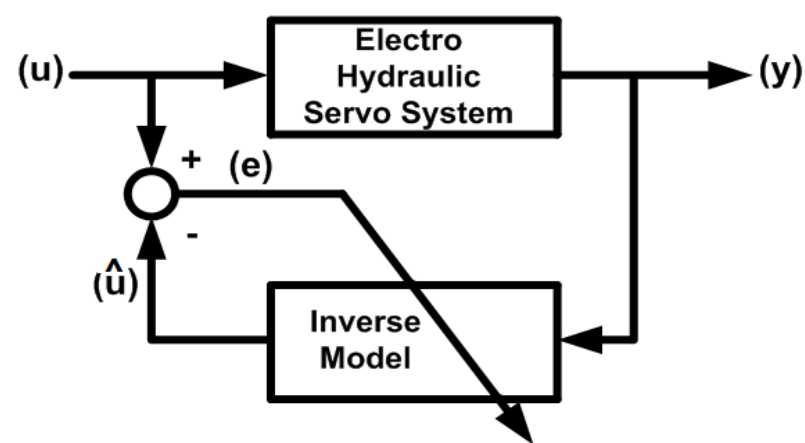

Fig.6: learning scheme for inverse neural network

The Back propagation algorithm is used for training the network with the input and target vectors, until it can associate input vectors with appropriate output vectors by using Neural Networks Toolbox User's Guide in Matlab Program [13]. 
The inverse model can be identified from a set of input-output data pairs. Its collected from numerical experiments. This is done by consider output- input to the neural network and vice-verse. These are given by the PPDCV model equations simulations. The sampling interval of $0.01 \mathrm{sec}$ was chosen.

The network is trained by Levenberg-Marquardt training algorithm for system identification of the inverse model. The Levenberg-Marquardt Algorithm (LMA) uses an iterative technique to reach the minimum of a multivariate function. The minimum of a multivariate function is expressed as the sum of squares of nonlinear real-valued functions [14].

Artificial neural networks are made up of a simplified individual models of the biological neuron that are connected together to form a network. The neural network topology on this paper has four layers: one input layer, two hidden layers and one output layer. The weighted inputs to a particular node are summed, and its resultant value is passed through nonlinear tan-sigmoid transfer activation function (tansig) to determine the output value of the node. The linear output neurons are used for fitting function problems with the linear transfer function.

The inverse neural network calculates the control action $u(t)$ based on the current and few previous histories of input and output data so that it can generate the desire control signal

\section{RESULTS \& DISCUSSION}

The simulations are carried out on the PPDCV model given by differential equations which are put together in MATLAB's function with Simulink block diagram format. The parameters of PPDCV system are given in Table 1. These parameters are used for the dynamic models of the electro hydraulic control system involved designing, control algorithm and the selecting a model structure, choosing a criterion to fit.

In order to perform the output response, we used PID controller and inverse neural network controller. We compare between these controllers for control PPDCV system. Each type of the controller should be submitted to sinusoidal input with and without parameters variation. The main subject of these controllers is that the actual output of the actuator position tracks the desired input without any disturbance and the response is smooth and not oscillated.

The inverse control method is the type of the neural network control that used to control PPDCV system. A sinusoidal input with peak to peak amplitude of $65 \mathrm{~mm}$ is used. Conventional PID controller is used to show the response as shown in Fig.7.

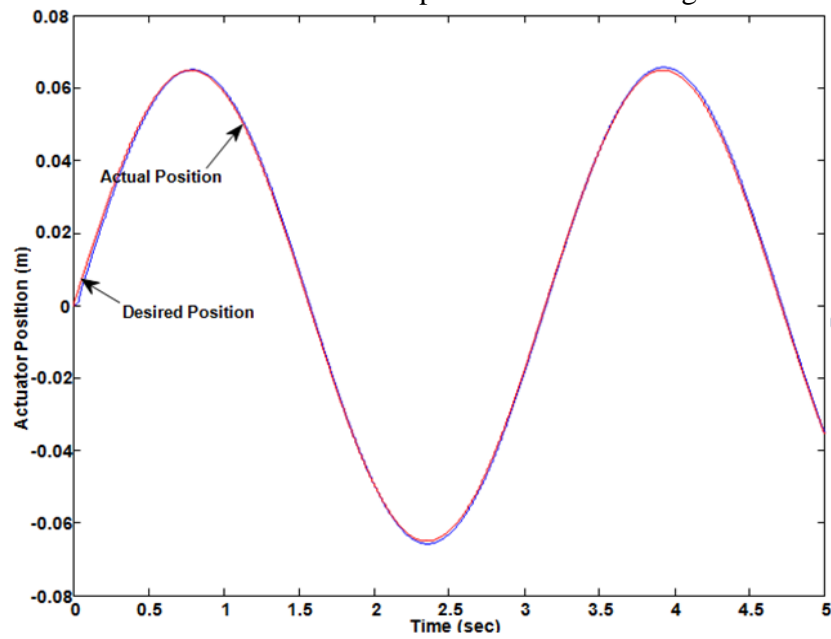

Fig.7 Sinusoidal response of PPDCV with PID controller
Table.1 Physical parameters for PPDCV system

\begin{tabular}{|c|c|c|c|}
\hline Parameter Name & $\begin{array}{c}\text { Parameter } \\
\text { symbol }\end{array}$ & $\begin{array}{c}\text { Parameter } \\
\text { value }\end{array}$ & Unit \\
\hline Width of the pilot valve port & $\mathrm{w}_{\text {pil }}$ & 0.001 & $\mathrm{M}$ \\
\hline $\begin{array}{l}\text { Supply pressure to the pilot } \\
\text { valve }\end{array}$ & $\mathrm{p}_{\mathrm{s} 1}$ & $3 * 10^{6}$ & $\mathrm{~Pa}$ \\
\hline $\begin{array}{l}\text { Natural frequency of the pilot } \\
\text { valve }\end{array}$ & $\mathrm{w}_{\mathrm{n}}$ & 120.4 & $\mathrm{rad} / \mathrm{s}$ \\
\hline $\begin{array}{l}\text { Pilot valve gain } \\
\end{array}$ & $\mathrm{k}$ & $4.9 e-4$ & $\mathrm{~m} / \mathrm{V}$ \\
\hline $\begin{array}{l}\text { Damping coefficient of the } \\
\text { pilot valve }\end{array}$ & $\xi$ & 0.7 & \\
\hline Width of the main valve port & $\mathrm{W}_{\text {main }}$ & 0.008 & $\mathrm{M}$ \\
\hline Effective bulk modulus & $\beta$ & $680 * 10^{6}$ & $\mathrm{~Pa}$ \\
\hline Hydraulic fluid density & $\rho$ & 870 & $\mathrm{~kg} / \mathrm{m}^{2}$ \\
\hline $\begin{array}{c}\text { Pilot Valve coefficient of } \\
\text { discharge }\end{array}$ & $\mathrm{c}_{\text {dpil }}$ & 0.6 & \\
\hline Main valve stroke length & $\mathrm{s}_{\text {main }}$ & \pm 15 & $\mathrm{~mm}$ \\
\hline Area of the main valve & $A_{\text {main }}$ & $4 * 10^{-4}$ & $\mathrm{~m}^{2}$ \\
\hline mass of the main valve & $\mathrm{M}_{\text {main }}$ & 1.75 & $\mathrm{~kg}$ \\
\hline Width of the main valve port & $\mathrm{w}_{\text {main }}$ & 0.008 & $\mathrm{M}$ \\
\hline $\begin{array}{c}\text { main valve coefficient of } \\
\text { discharge }\end{array}$ & $\mathrm{c}_{\text {dmain }}$ & 0.6 & \\
\hline $\begin{array}{c}\text { Main valve Viscous damping } \\
\text { coefficient }\end{array}$ & $\mathrm{b}_{\text {main }}$ & 70 & N. s/m \\
\hline Main valve stiffness & $\mathrm{k}_{\text {main }}$ & 700 & $\mathrm{~N} / \mathrm{m}$ \\
\hline $\begin{array}{c}\text { Supply pressure to the main } \\
\text { valve }\end{array}$ & $\mathrm{p}_{\mathrm{s} 2}$ & $5 * 10^{6}$ & $\mathrm{~Pa}$ \\
\hline Actuator stroke length & $\mathrm{S}_{\mathrm{act}}$ & 0.13 & $\mathrm{M}$ \\
\hline Actuator piston area & $A_{\text {act } A}$ & 0.038 & $\mathrm{~m}^{2}$ \\
\hline Actuator annulus area & $A_{\text {actB }}$ & 0.0192 & $\mathrm{~m}^{2}$ \\
\hline Rod actuator mass & $\mathrm{M}_{\mathrm{act}}$ & 50 & $\mathrm{Kg}$ \\
\hline $\begin{array}{c}\text { Actuator Viscous damping } \\
\text { coefficient }\end{array}$ & $\mathrm{b}_{\mathrm{act}}$ & 8500 & $\mathrm{Ns} / \mathrm{m}$ \\
\hline Actuator stiffness & $\mathrm{k}_{\mathrm{act}}$ & 900 & $\mathrm{~N} / \mathrm{m}$ \\
\hline
\end{tabular}

When neural network controller is used instead of PID controller with same sinusoidal input, it can show that both controllers (PID $\& N N$ ) has similar performance shown in Fig.8.

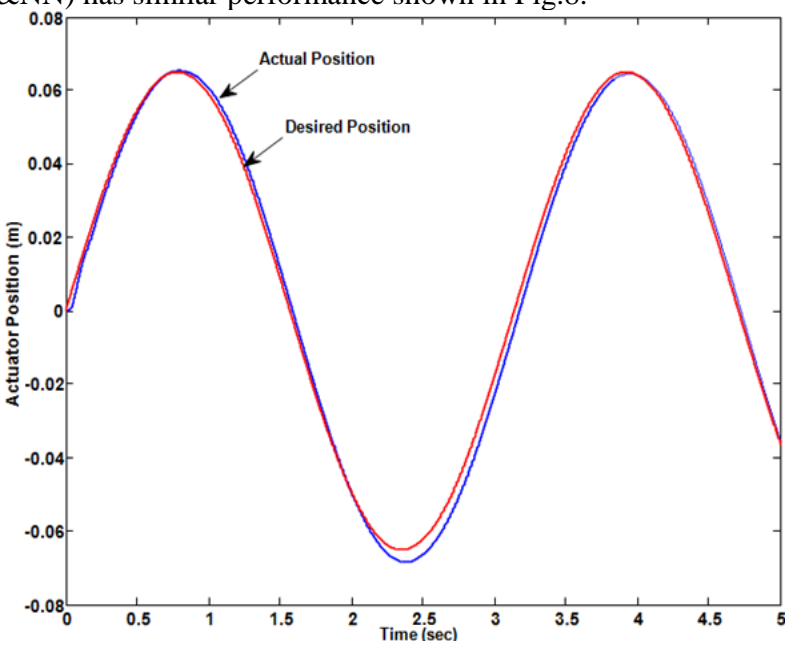

Fig.8 Sinusoidal response of PPDCV with NN controller

The parameter variation of the pressure sources parameter is occasionally happens in the system. It changes the pilot valve pressure to $(5 \mathrm{MPa})$ and the main valve pressure to $(7 \mathrm{MPa})$.

When the sinusoidal input is also used with PID such the previous case, but with parameter variation that mentioned above, it can be show that the actual output has a disturbance and oscillated response as shown in below Figures $(9,10)$. 


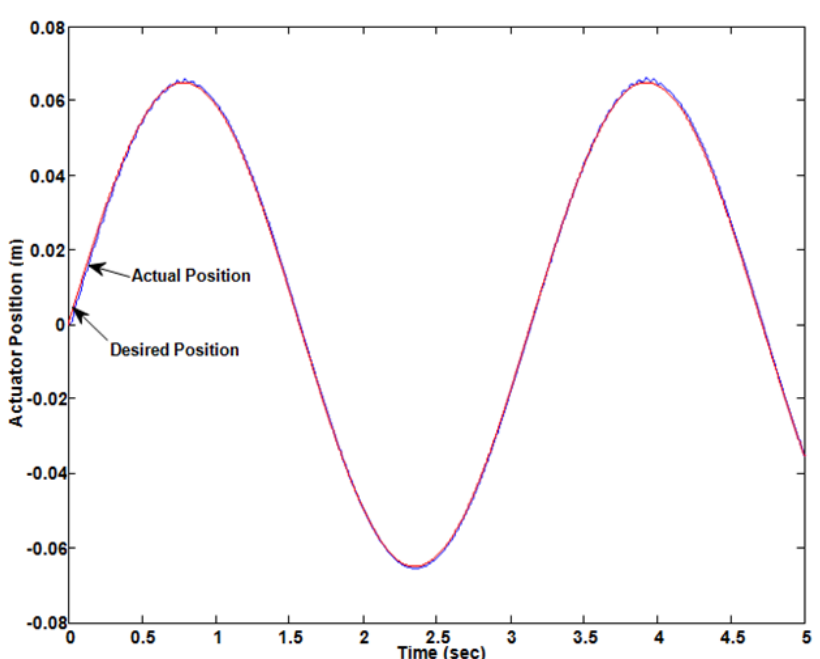

Fig.9 Sinusoidal response of PPDCV by PID controller with parameter variation

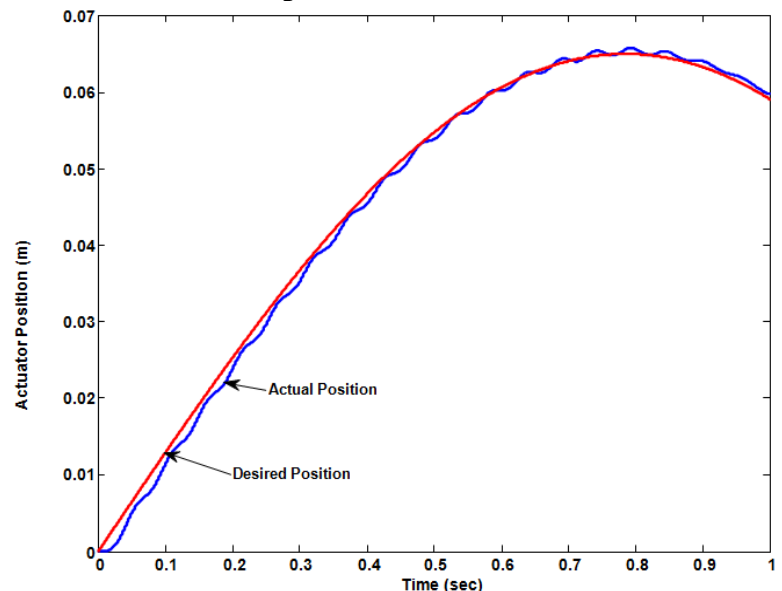

Fig.10 Sinusoidal response by PID controller with parameter variation (short time)

The disturbance is eliminated when using NN controller and the response is not oscillating. The actuator response with the parameter variation condition is maintained to be similar as the response in the nominal working condition when used NN controller. These are show in below Figures $(11,12)$ with small time.

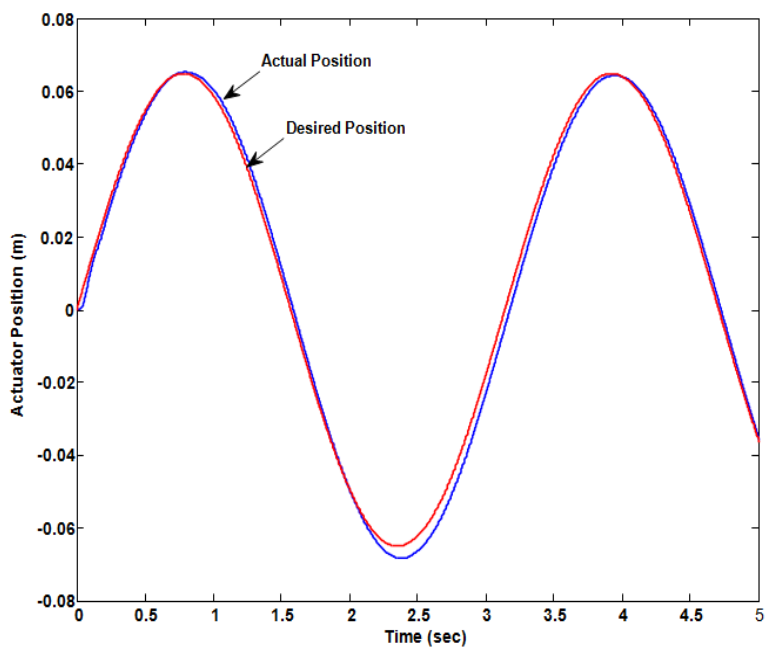

Fig.11 Sinusoidal response of PPDCV by NN controller with parameter variation

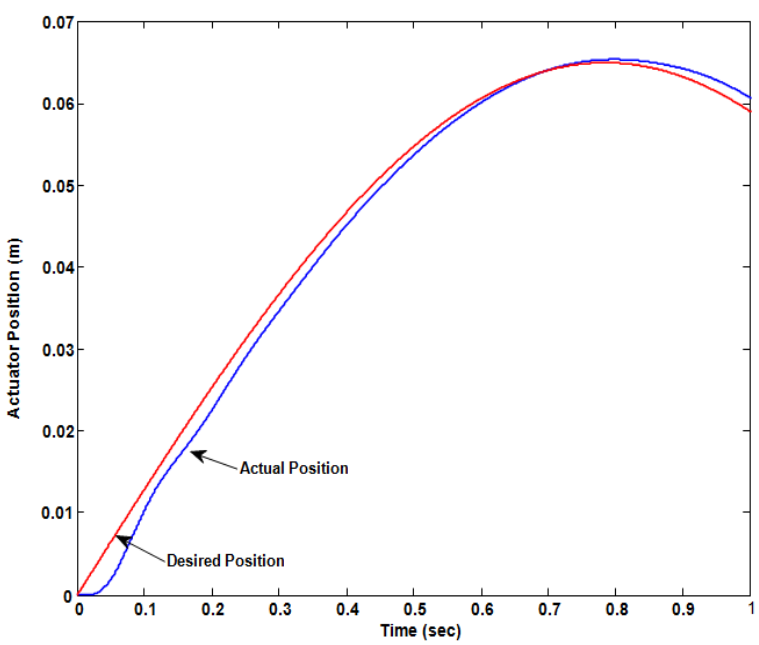

Fig.12 Sinusoidal response of PPDCV by NN controller with parameter variation (short time)

\section{CONCLUSIONS}

This paper presents a neural network control for PPDCV technique to control the position of the actuator. The response of the actuator position can show the effect of the parameters variation during simulation time. These parameters variations are occasionally happen. It causes a disturbance and unsmooth response when used conventional PID controller. Neural network controller is designed instead of PID controller, and it's used with not well known plant or uncertainty parameter while input output data are available. Neural network are used to model the inverse of PPDCV system for design inverse controller. The test of the simulation showed that the neural controller is still stable even significant disturbances occurred when the parameters variation, and the oscillated response is removed.

\section{REFERNCES}

[1] Yung C. Shin and Chengying Xu. 2008. Intelligent Systems Modeling, Optimization, and Control. Taylor \& Francis Group, LLC.

[2] M. Norgaard, et al. 2000. Neural Networks for Modeling and Control of Dynamic Systems. A Practitioner's Handbook. Springer, Boston, MA.

[3] O. A. Dahunsi, J. et al. September 2010. System Identification and Neural Network Based PID Control of Servo - Hydraulic Vehicle Suspension System. South African Institute of Electrical Engineers; 101(3).93-105.

[4] A. A. Mozafari and M. Lahroodi. April 2008. Modeling and Control of Gas Turbine Combustor with Dynamic and Adaptive Neural Networks. IJE Transactions B. Applications; 21(1). 71-84.

[5] Ammar A. Aldair and Weiji J. Wang. June 2011. Neural Controller Based Full Vehicle Nonlinear Active Suspension Systems with Hydraulic Actuators. International Journal of Control and Automation; 4(2). 7994.

[6] A. Khajekaramodin et al. Aug 2007. Semi-active Control of Structures Using Neuro-Inverse Model of MR Dampers. First Joint Congress on Fuzzy and Intelligent Systems Ferdowsi in University of Mashhad.

[7] Wenjun Meng, Zhanlin and Wang Lihua Qiu. June 18-21, 2007. Analysis for Neural Network Controllers and Passivity-Based Controller on Test System for Aero 
Hydraulic Pump. 12thIFToMM World Congress, Besançon (France).

[8] Zhen-Yuan, et al. 2010. Characteristics Forecasting of Hydraulic Valve Based on Grey Correlation and ANFIS. Expert Systems with Applications 37. 1250-1255.

[9] Jyh-Chyang,et al. 2008. Modeling and Control of a New 1/4T Servo-Hydraulic Vehicle Active Suspension System. Journal of Marine Science and Technology; 15(3). 265272.

[10] Parker Hannifin GmbH \& Co. KG. 2009. Manual Series DF plus XG099.

[11] Majid Ahmed Oleiwi and Zaid Abed Aljasem. September 2013. Position Control for (PPDCV) Using PID \& Fuzzy
Supervisory Controller. Academic Research International; 4(5). 110-128.

[12] Bohdan T. et al. 2007. Dynamic Modeling and Control of Engineering Systems. Third Edition, John F. Gardner,

[13] Mark Hudson Beale, et al. 2013. Neural Networks Toolbox User's Guide. The Math Works, Inc.

[14] Lera G. and M. Pinzolas. 2002. Neighborhood Based Levenberg-Marquardt Algorithm for Neural Network Training. IEEE Transactions on Neural Networks; 13(5).1200-1203.

[15] D.Scholz. 1996. Proportional hydraulics. Festo Didactic KG, D73734 Esslingen, Textbook. 